November 1999 - NREL/CP-500-27151

\title{
Using Time-Frequency and Wavelet Analysis to Assess Turbulence/Rotor Interactions
}

\author{
Preprint
}

N.D. Kelley and R.M. Osgood

National Renewable Energy Laboratory

J.T. Bialasiewicz and A. Jakubowski University of Colorado at Denver

To be presented at the $19^{\text {th }}$ American Society of Mechanical Engineers (ASME) Wind Energy Symposium Reno, Nevada January 10-13, 2000

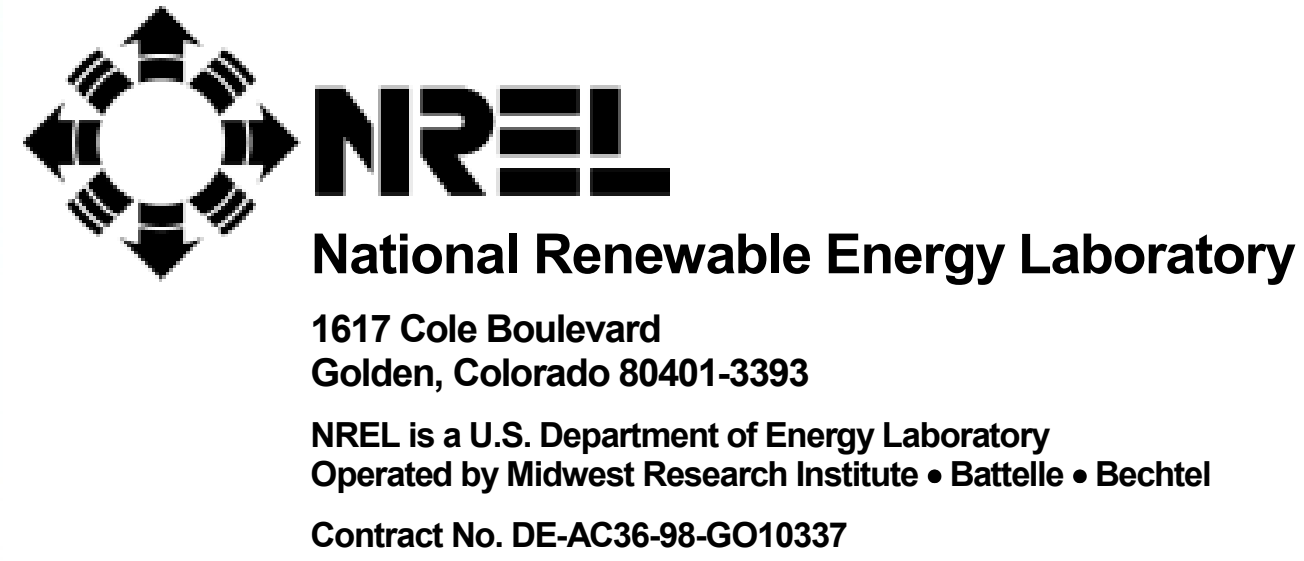




\section{NOTICE}

The submitted manuscript has been offered by an employee of the Midwest Research Institute (MRI), a contractor of the US Government under Contract No. DE-AC36-99G010337. Accordingly, the US Government and MRI retain a nonexclusive royalty-free license to publish or reproduce the published form of this contribution, or allow others to do so, for US Government purposes.

This report was prepared as an account of work sponsored by an agency of the United States government. Neither the United States government nor any agency thereof, nor any of their employees, makes any warranty, express or implied, or assumes any legal liability or responsibility for the accuracy, completeness, or usefulness of any information, apparatus, product, or process disclosed, or represents that its use would not infringe privately owned rights. Reference herein to any specific commercial product, process, or service by trade name, trademark, manufacturer, or otherwise does not necessarily constitute or imply its endorsement, recommendation, or favoring by the United States government or any agency thereof. The views and opinions of authors expressed herein do not necessarily state or reflect those of the United States government or any agency thereof.

Available electronically at http://www.doe.gov/bridge

Available for a processing fee to U.S. Department of Energy and its contractors, in paper, from:

U.S. Department of Energy

Office of Scientific and Technical Information

P.O. Box 62

Oak Ridge, TN 37831-0062

phone: 865.576 .8401

fax: 865.576.5728

email: reports@adonis.osti.gov

Available for sale to the public, in paper, from:

U.S. Department of Commerce

National Technical Information Service

5285 Port Royal Road

Springfield, VA 22161

phone: 800.553 .6847

fax: 703.605.6900

email: orders@ntis.fedworld.gov

online ordering: http://www.ntis.gov/ordering.htm

Printed on paper containing at least $50 \%$ wastepaper, including $20 \%$ postconsumer waste 


\title{
USING TIME-FREQUENCY AND WAVELET ANALYSIS ${ }^{* \dagger}$ TO ASSESS TURBULENCE/ROTOR INTERACTIONS
}

\author{
Neil D. Kelley \\ Richard M. Osgood \\ National Renewable Energy Laboratory \\ Golden, Colorado \\ Jan T. Bialasiewicz ${ }^{\text {II }}$ \\ Andrzej Jakubowski ${ }^{\#}$ \\ University of Colorado at Denver \\ Denver, Colorado
}

\begin{abstract}
Large loading events on wind turbine rotor blades are often associated with transient bursts of coherent turbulent energy in the turbine inflow. These coherent turbulent structures are identified as peaks in the three-dimensional, instantaneous, turbulent shearing stress field. Such organized inflow structures and the accompanying rotor aeroelastic responses typically have time scales of only a few seconds and therefore do not lend themselves for analysis by conventional Fourier spectral techniques. Time-frequency analysis (and wavelet analysis in particular) offers the ability to more closely study the spectral decomposition of short period events such as the interaction of coherent turbulence with a moving rotor blade.

In this paper, we discuss our initial progress in the application of time-frequency analysis techniques to the decomposition and interpretation of turbulence/rotor interaction. We discuss the results of applying both the continuous and discrete wavelet transforms for our application. Several examples are given of the techniques applied to both observed turbulence and turbine responses and those generated using numerical simulations. We found that the presence of coherent turbulent structures, as revealed by the inflow Reynolds stress field, is a major contributor to large load excursions. These bursts of coherent turbulent energy induce a broadband

\footnotetext{
subject to copyright protection in the United States.

This work has been supported by the U.S. Department of Energy under contract no. DE-AC36-98-GO10337.

Principal Scientist, National Wind Technology Center, Senior AIAA Member

${ }^{\S}$ Senior Engineer, National Wind Technology Center

II Professor, Department of Electrical Engineering

\# Graduate Student, Department of Electrical Engineering
}

* This paper is a declared work of the U.S. Government and is not
\end{abstract}

aeroelastic response in the turbine rotor as it passes through them.

\section{INTRODUCTION}

Identifying the processes responsible for inducing large loading events on wind turbine rotors remains one of the major unanswered questions of the technology. We know that such events can occur during large yaw excursions or during periods of sustained operation at large yaw angles. Previously we identified large loading events resulting from the interaction of the turbine rotor with organized or coherent turbulent structures in the inflow. ${ }^{1} \mathrm{We}$ found that the number of cycles contained in the high-loading tails of spectral distributions scales with the hub-height or local mean shearing stress $u_{*}$ and the turbine layer vertical stability. The mean shearing stress or friction velocity is defined as

$$
u_{*}=\sqrt{\left|\overline{u^{\prime} w^{\prime}}\right|}
$$

where $u^{\prime}$ and $w^{\prime}$ are the longitudinal and vertical zeromean wind components aligned with the mean shear vector. The turbine layer is defined as the vertical distance between the ground and the maximum elevation of the rotor. The vertical stability is expressed by the gradient Richardson number defined as

$$
\left.R i=\left(g / \theta_{\mathrm{m}}\right) \mid(\partial \bar{\theta} / \partial z) /(\partial \bar{u} / \partial \mathrm{z})^{2}\right\rfloor,
$$

where $\mathrm{g}$ is the gravity acceleration, $z$ the height in meters, $\theta_{m}$ the layer mean thermodynamic potential temperature $(\mathrm{K})$ given by

$$
\theta(z)=T(z)\left[(1000 / p(z)]^{0.286},\right.
$$

and $T(z)$ and $p(z)$ are the temperature $(\mathrm{K})$ and barometric pressure (hPa) at height $z$. 


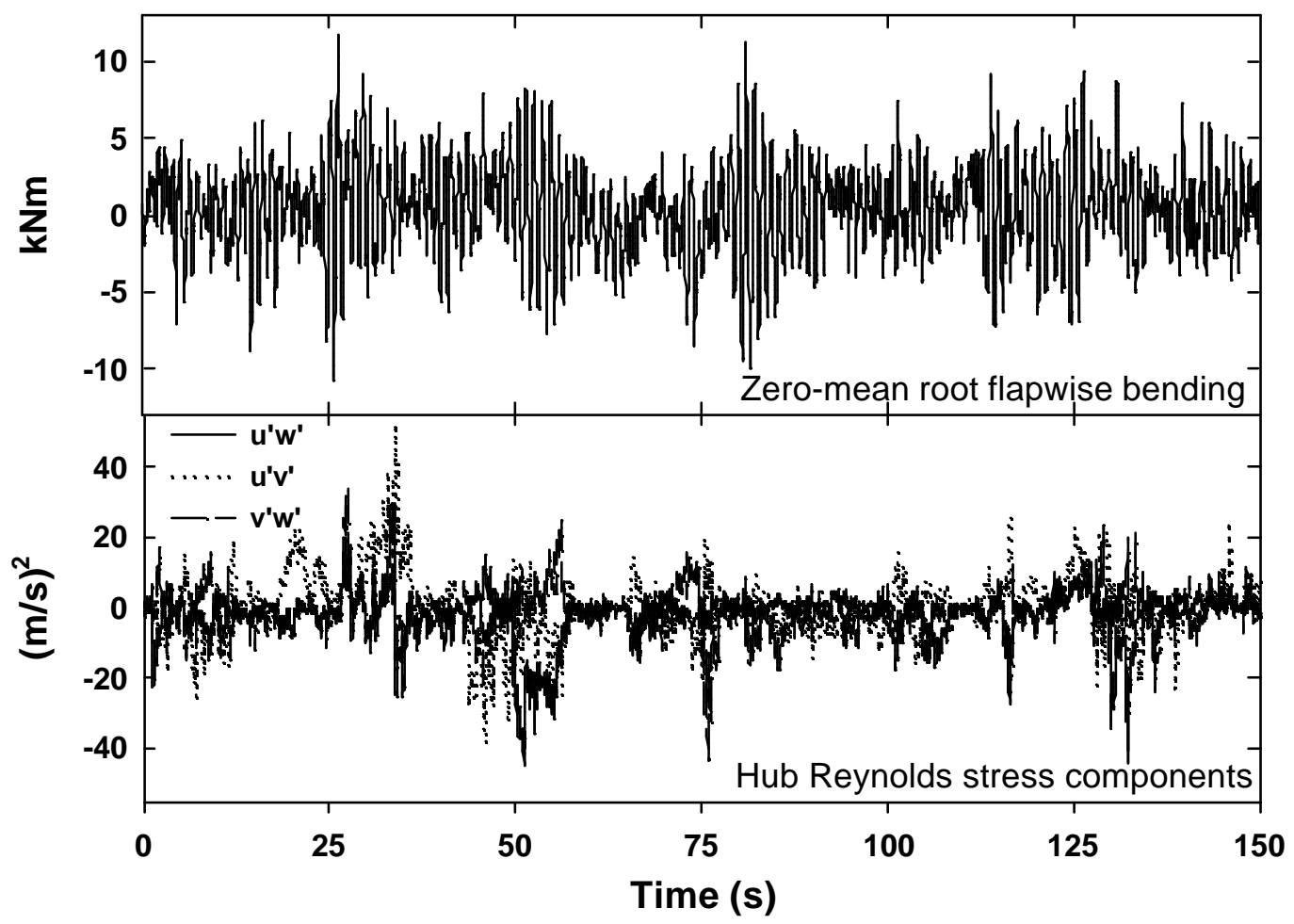

Figure 1. Example of rotor flapwise load excursions and corresponding hub-height, instantaneous Reynolds stresses

The covariance, $\overline{u^{\prime} w^{\prime}}$, represents one component of the mean Reynolds stresses in turbulent flow. The others include $\overline{u^{\prime} v^{\prime}}$ and $\overline{v^{\prime} w^{\prime}}$, where $v^{\prime}$ is zero-mean, lateral wind component. In a well-mixed, homogeneous boundary layer, only $\overline{u^{\prime} w^{\prime}}$ is generally non-zero. However, when turbulence contains motions that are both spatially and temporally organized; i.e., there is a definite phase structure between the velocity components, all three mean Reynolds stress components can be finite. Instantaneously, all three components can take on large positive or negative values. The passage of an organized patch of turbulence can be identified using an anemometer capable of the rapid, simultaneous measurement of multi-axis wind components. Coherent turbulent structures can contain large velocity shears over small distances as well as significant local vorticity. Moderate to high-speed flows that are just slightly or weakly stable ( $R i$ small, but positive) often contain small, energetic turbulence structures that, when ingested by wind turbine rotors, increase fatigue damage. ${ }^{2}$

The examination of many load histories with the corresponding three instantaneous Reynolds stress components has supported the conclusions reached from the statistical analyses; i.e., significant loading events are often related to the ingestion of coherent turbulent structures. Figure 1 demonstrates this connection. Here the actual zero-mean time history of a turbine rotor flapwise load and the corresponding instantaneous Reynolds stress components, derived from a multi-axis sonic anemometer mounted on a tower upstream of the turbine, are presented. Because the turbulence measurement is upstream from the rotor, the stress/load time relationships may not be accurate because of the propagation delay. It is also possible that, because of a skewed flow, the indicated turbulence patch may not been seen by the turbine and vice versa.

Figure 1 clearly demonstrates the issue. We are very much interested in the details of the turbulent inflow responsible for the tensile and compression loading peaks. The loading extremes residing within these peaks define the stress cycles seen in the high amplitude tails of loading spectral distributions. We would like to be able to identify the characteristics of the turbulent structure, which through the action of the turbulence/rotor interaction, produce the observed understand the atmospheric conditions that produce 

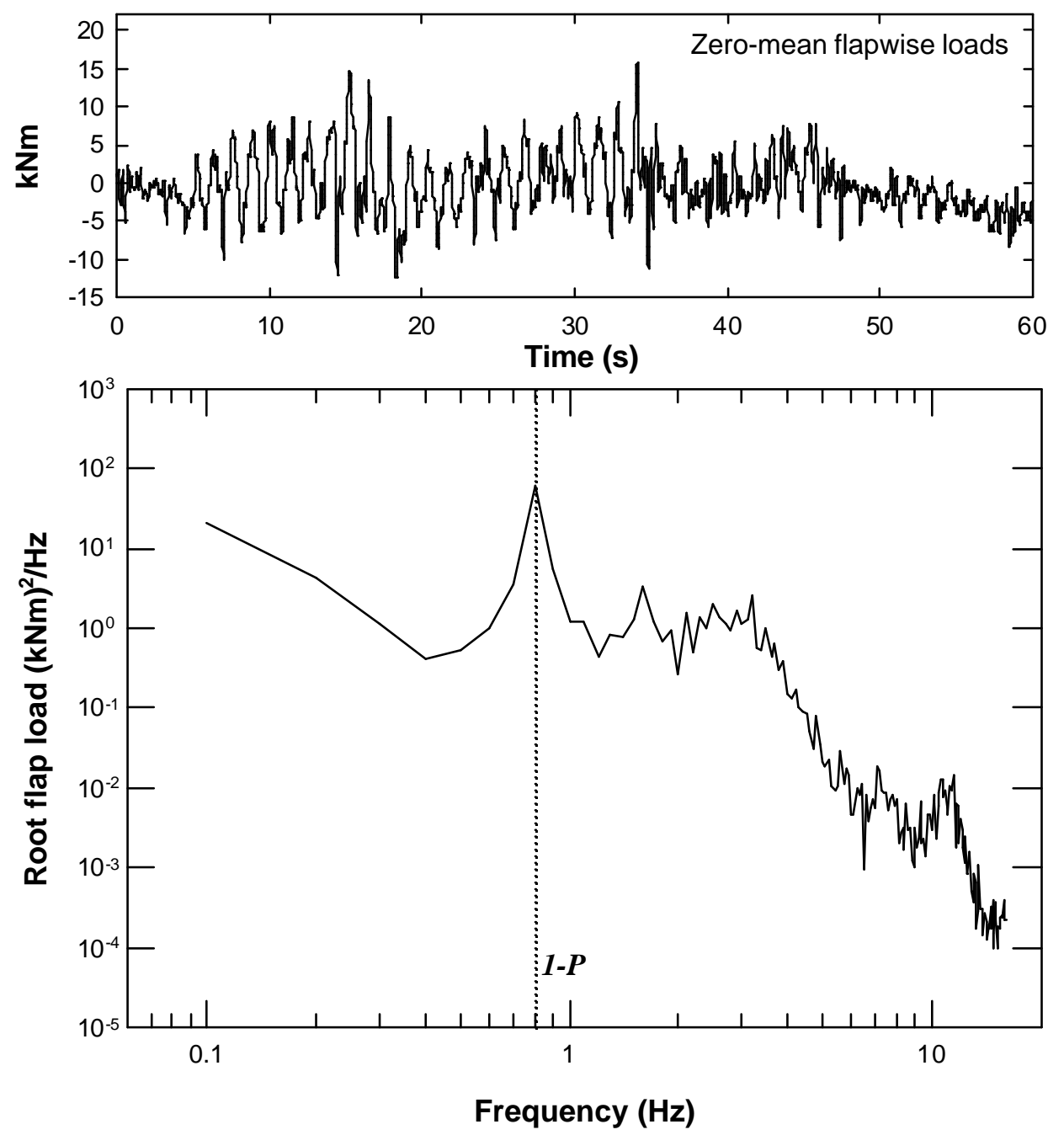

Figure 2. Example of conventional power spectrum of non-stationary flapwise time history

aeroelastic response. Further, we would like to understand the atmospheric conditions that produce such structures and to be able to numerically simulate them. Finally, we wish to understand the details of the aerodynamic/aeroelastic processes involved in order to improve our unsteady aerodynamics models and to use those models as a tool in developing load mitigation strategies.

The time-series of Figure 1 represent examples of non-stationary processes. The turbulent bursts in the Reynolds stress field can produce a short-lived aeroelastic response in the root loads of the turbine rotor. In analyzing this response, we wish to examine the excitation and response in the frequency domain. Conventional spectral techniques are based on time histories being at least "quasi-stationary", i.e., the statistics of the signal are not changing with time or at least changing very slowly over the period of the record. Clearly, that is not the case with any of the signals depicted in Figure 1. The use of conventional spectral analysis of a flapwise loading signal that is changing characteristics until the influence a shortlived turbulent burst is demonstrated in Figure 2. The spectrum of this signal has excellent frequency resolution $(0.1 \mathrm{~Hz})$. However, one cannot tell what the spectral energy distribution is in the 0 to 5 and 35 to 60 second portions of the record relative to the large excursions seen between 5 and 35 seconds. We say the spectrum of Figure 2 has very good frequency resolution or localization but very poor time resolution or localization. In fact, the time localization is the record length itself.

We wish to identify suitable techniques to allow us to dissect important frequency domain information from loading events that typically last only on the order of 10 seconds or less. We would like to use that information to understand the nature of the turbulence field excitation and the forced responses 
of the turbine rotor that result in large load excursions and significant fatigue damage. In this paper, we discuss our initial progress in developing a methodology to allow us to achieve these objectives.

\section{APPROACH}

We need to identify an analytical tool or collection of tools that allow us to perform a "local" analysis of transient loading events seen in the turbine rotor loading histories and their associated turbulent inflow structures. Conventional Fourier spectral analysis does not meet this criteria. Our approach is to evaluate the capabilities of what is generally known as Time-Frequency Analysis and its sub-discipline, Wavelet Analysis. We examined both observed and simulated turbine inflows and resulting aeroelastic responses afforded us by these analysis techniques.

Specifically, we report on our progress in

- Identifying the most promising techniques available in the analysis of transient signals that can be applied to the excitation and response of wind turbine rotors

- Analyzing both the inflow Reynolds stress and root flapwise rotor response time histories derived from field measurements from a relatively rigid turbine design (Micon 65) and a very flexible one (Wind Eagle CWE300) using several of the identified techniques

- Analyzing the results of a numerical simulation of the very flexible turbine design including parameters measured in the rotational frame not available from actual observations

- Reaching initial conclusions about the applicability of these techniques to understanding the turbulence/rotor interaction and its role in transient load events.

\section{AN EVALUATION OF TIME-FREQUENCY ANALYSIS TOOLS}

Our goal in this study is to evaluate various timefrequency and wavelet analysis techniques that allow us to obtain an estimate of the frequency content of a signal locally at a particular point in time. This way we can assess the impact of short-lived inflow transients on the aeroelastic response of a wind turbine rotor and their relationship to large stress cycles and fatigue accumulation.

Linear time-frequency transforms correlate the signal being analyzed with a family of waveforms that are well-localized in time and frequency. ${ }^{3}$ Two of the most important classes of these families are the Windowed Fourier and wavelet transforms. In our study we evaluated examples of both classes using wind turbine related signals such as the instantaneous shearing stresses and flapwise load signals. We applied the Windowed Fourier transform (sometimes referred to as the Short Time Fourier Transform or STFT) through an analysis procedure called the spectrogram using various window functions. It measures the energy in a time-frequency neighborhood, $f_{i}, t_{i}$ specified by a resolution box (called a Heisenberg box) bounded by $\sigma_{f} \sigma_{t}$. We applied the same procedure using the wavelet transform (now called a scalogram) and various analyzing wavelet functions. While each approach has its advantages and disadvantages, we found that (at least for a constant-speed turbine) these techniques did not offer us any additional information over the continuous and discrete wavelet transforms discussed below. We now provide a brief discussion of the theory behind the specific analysis techniques employed in this research.

Wavelets are a powerful tool for studying timefrequency behavior of finite-energy signals. The advantages of the wavelet decomposition over Fourier transforms present themselves when transforming a signal that has time varying and/or singularity characteristics. Multiresolution and wavelet theory has recently found applications in a remarkable range of disciplines such as data compression, signal processing, image analysis, statistics, and modeling of nonlinear dynamic processes. An excellent presentation of the subject is given by Mallat. ${ }^{3}$ Note: It is not the intention of this short section to give a broad introduction to the subject or a long list of references. In this research, we apply wavelet analysis to establish the relationship between the turbulent wind and the mechanical loads in the blades of the wind turbine. We use both discrete and continuous wavelet transforms to obtain the best possible presentation of the mechanical loads of the relatively stiff blades of the Micon 65 turbine and the very flexible blades of the CWE300 machine. Since wavelet analysis of signals is a new technique we start with its brief presentation.

\section{The Continuous Wavelet Transform (CWT)}

The continuous wavelet transform $W f(s, b)$ of a finite-energy signal $f(t)$ is defined as its scalar product with the wavelet $\psi_{s b}(t)$. In other words, the wavelet transform represents the correlation of the signal $f(t)$ and the wavelet $\psi_{s b}(t)$. In addition, due to Parseval's theorem, this relationship can also be stated in the frequency domain. The following equation gives both representations: 


$$
\begin{aligned}
W f(s, b) & =\int_{-\infty}^{\infty} \psi_{s b}(t) f(t) d t \\
& =\frac{1}{2 \pi} \int_{-\infty}^{\infty} \hat{f}(\omega) \hat{\psi}^{*}(s \omega) e^{j b \omega} d \omega
\end{aligned}
$$

where the wavelet

$$
\psi_{s b}(t)=s^{-1 / 2} \psi\left(s^{-1}(t-b)\right), s \in \mathbf{R}^{+}, b \in \mathbf{R}
$$

and $\psi(t)$, known as the mother wavelet, is a function, which satisfies the following equation:

$$
\int_{-\infty}^{\infty} \psi(t) d t=0 .
$$

One such function, which we used in our research, is the Morlet wavelet, shown in Figure 3. We chose this analyzing wavelet because it is symmetrical and exhibits a linear phase response. It can be seen from equation (2) that the parameters $s$ and $b$ in equation (1) can be interpreted as the scale and the translation. The mother wavelet corresponds to scale $s=1$. The increase of $s$ is equivalent to stretching the mother wavelet or moving its frequency content towards lower frequencies. On the contrary, the decrease of $s$ causes the compression of the mother wavelet or moving its frequency content towards higher frequencies. Varying $b$ for the fixed scale corresponds to sliding a wavelet with a fixed bandwidth and with some center frequency along the analyzed signal. For a given position $b$ of the analyzing wavelet, we calculate the value of the wavelet transform. It tells us, to what extent the frequency content of the analyzed signal, in the neighborhood of $b$, is close to the frequency content of the wavelet at the given scale $s$.

To make the described procedure useful, we have to establish the relationship between the scale $s$ and the frequency content, at this scale, of a particular analyzing wavelet. This is accomplished by defining two frequency characteristics of the mother wavelet ${ }^{1}$, the center frequency

$$
\omega_{0}=\frac{1}{2 \pi} \int_{0}^{\infty} \omega|\hat{\psi}(\omega)|^{2} d \omega,
$$

and the bandwidth $B_{0}=\sigma_{\omega}$, centered around $\omega_{0}$, with

$$
\sigma_{\omega}^{2}=\frac{1}{2 \pi} \int_{0}^{\infty}\left(\omega-\omega_{0}\right)^{2}|\hat{\psi}(\omega)|^{2} d \omega .
$$

For a wavelet of the scale $s$, the center frequency and the bandwidth are, respectively, defined by the following equations:

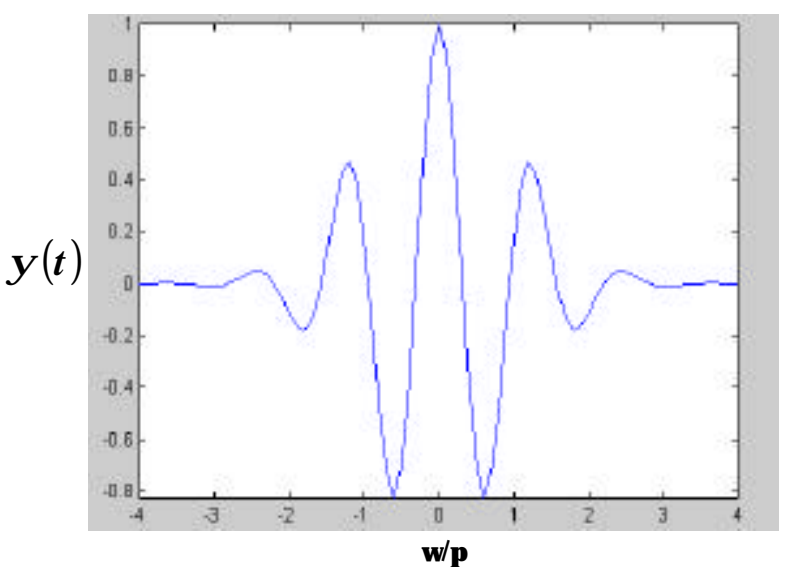

Figure 3. The Morlet wavelet

$$
\omega_{s}=\frac{\omega_{0}}{s}, B_{s}=\frac{B_{0}}{s}=\frac{\omega_{\max }-\omega_{\min }}{s},
$$

with $\omega_{\max }=\omega_{0}+B_{0} / 2, \omega_{\min }=\omega_{0}-B_{0} / 2$. Note that by this convention $B_{0}=B_{1}$ and $\omega_{0}=\omega_{1}$

It is very important to note that both the center frequency and the bandwidth have different values for every wavelet. In other words, it is important to choose the mother wavelet with high frequency resolution or the narrow bandwidth. The increase of the scale $s$ improves the frequency resolution at lower frequencies.

In practice, for both continuous-time and discrete-time wavelet signal analysis, we have to use the discrete-time representation of the analyzed signal. This signal is sampled with some frequency $\omega_{T}$, where $T$ is the sampling period. In this case, the bandwidth of the sampled signal is limited by the Nyquist frequency $1 / 2 \omega_{T}$. The frequency variation of the continuous-time signal between 0 and $1 / 2 \omega_{T}$ corresponds to the representative point moving between these values in the complex plane $s$ along imaginary axis. However, the corresponding frequency variation of the discrete signal should be represented in the complex plane $z$. The mapping between the imaginary axis of the $s$ plane, for which $s=j \omega$ is determined by the following equation:

$$
z=e^{i \omega t} \text { or } \angle z=\omega T,|z|=1,
$$

which means that when the frequency of the continuous-time signal varies in the interval $[0$, $\left.1 / 2 \omega_{T}\right]$, the angle or the frequency of the discretetime signal, represented in radian units, varies in the interval $[0, \pi]$. This is justified by the following calculation: 


$$
\left.\angle z\right|_{\omega_{T} / 2}=\frac{\omega_{T}}{2} \frac{2 \pi}{\omega_{T}}=\pi .
$$

In other words the frequency of $1 / 2 \omega_{T} \mathrm{rad} / \mathrm{s}$ of the continuous-time signal is represented by the frequency of $\pi$ radians of the discrete-time signal. This justifies the use of the relative frequency of the discrete-time signal, which is obtained by dividing, by $\pi$, every frequency $\omega$ from the interval $[0, \pi]$. Then, the relative frequency $\omega / \pi=1$ corresponds to the highest frequency of the continuous-time signal preserved in the sampled signal, i.e., the frequency $1 / 2 \omega_{T} \mathrm{rad} / \mathrm{s}$ or the frequency $1 / 2 f_{T} \mathrm{~Hz}$, with $\omega_{T}=2 \pi f_{T}$. It is convenient to represent the magnitude of the Fourier transform of the wavelets with different scales as a function of the relative frequency. Then, we obtain the real frequency value multiplying the relative frequency by the sampling frequency represented in radians per second or in Hertz.

The magnitude of the Fourier transform of the Morlet wavelet for several scales $s(s=1,2,3,4,5)$ is represented in Figure 4. The Morlet mother wavelet is given by the following equation:

$$
\psi(t)=e^{-t^{2} / 2} \cos (5 t)
$$

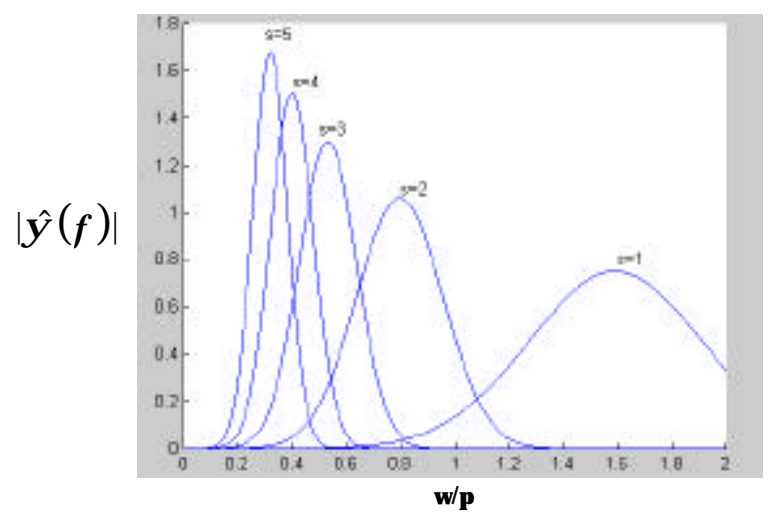

Figure 4. Magnitude of the Fourier transform of Morlet wavelet

For the Morlet wavelet $\omega_{0}=5$ and $B_{0}=1.701$ (radian units). Using these two parameters, we can determine $\omega_{s}$ and $B_{s}$ for any value of $s$. It is clear from Figure 4 that the magnitude of the Fourier transform of the Morlet wavelet for $s=1$ is almost entirely positioned to the right of $\omega / \pi=1$ or to the right of the Nyquist frequency. In other words, it is almost completely uncorrelated with the discrete representation of the original signal or the useful bandwidth of the Morlet mother wavelet is almost entirely above the half of the sampling frequency. It is apparent from this figure that the frequency resolution is much better for the lower relative frequencies (or for the lower scales). This immediately offers a solution to the problem of poor resolution at higher frequencies, i.e., the analyzed signal can be over-sampled at such a rate that lower scales and, in particular, scale equal one will not contain any useful frequencies. In other words, the bands of the lower scale wavelets (or wavelets with frequency resolutions too small for the performed analysis) will be outside the essential bandwidth of the analyzed signal.

It turns out that both the center frequency and the bandwidth of the wavelet, represented as a function of the scale $s$ on the log-log scale, are linear and provide direct scale to frequency conversion. This is very important for the understanding and the interpretation of the results of the wavelet analysis of signals.

In the data acquisition for the CWE300 turbine, we used a pre-sampling filter with a cut-off frequency of $40 \mathrm{~Hz}$ and a sampling rate of 200/s, i.e., we over-sampled the signals five times. We initially obtained very good frequency resolution in the relatively low-frequency bandwidth of interest. However, for the Micon 65, the pre-sampling filter and sampling rate used were $13 \mathrm{~Hz}$ and 32/s respectively. Further, the sampling rate available from the numerical simulation of the CWE300 turbine was only 60/s. Clearly the temporal resolution of the original Micon 65 signals were inadequate to achieve good frequency resolution over the range of interest and the simulated results could

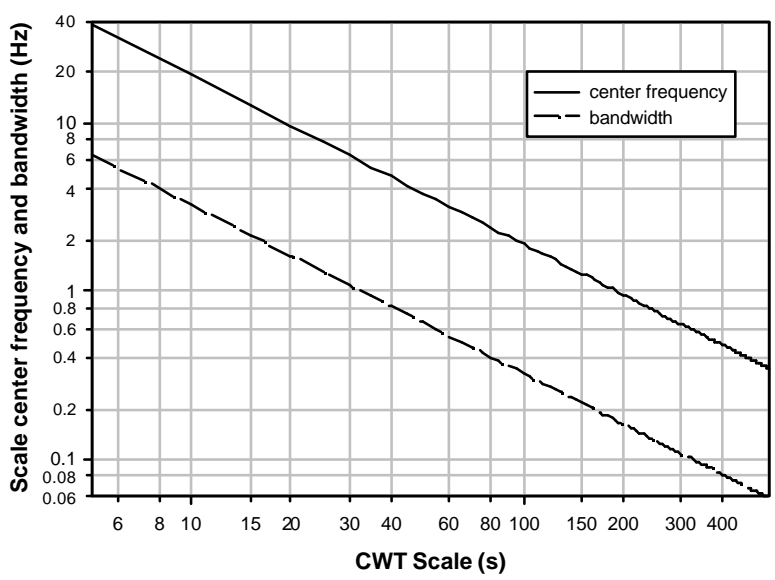

Figure 5. Continuous transform scale-tofrequency conversion/bandwidth for Morlet wavelet at 240/s sampling frequency 
be improved. In order to accommodate these requirements, we over-sampled each by linear interpolation to achieve a sampling rate of 240/s. The scale-to-frequency conversion characteristics for the Morlet wavelet and this sampling rate are shown in Figure 5. It should noted, as can be seen in Figure 4 , that the individual wavelet passbands do have some overlap that, in effect, reduces the frequency localization or discrimination.

\section{The Discrete Wavelet Transform (DWT)}

We shall now discuss the discrete wavelet transform. As a result of the quantization of the parameters $s$ and $b$, we obtain the following equation, which corresponds to equation (2)

$$
\psi_{m n}(t)=a_{0}^{-m / 2} \psi\left(a_{0}^{-m} t-n b_{0}\right)_{(m, n) \in \mathbf{Z}^{2}} .
$$

In particular, we can choose $a_{0}=2$ and $b_{0}=1$ and obtain the following dyadic orthonormal wavelet basis of the $L^{2}(\mathbf{R})$ space:

$$
\psi_{m n}(t)=2^{-m / 2} \psi\left(2^{-m}\left(t-2^{m} n\right)\right) .
$$

Note that for a fixed value of $m$ we have a constant scale $2^{m}$. Using $\psi_{m 0}(t)$ as a basic wavelet at the level $m$, we can rewrite (8) as

$$
\psi_{m n}=\psi_{m 0}\left(t-2^{m} n\right),
$$

which means that $2^{m}$ is the time step of shifting the wavelet $\psi_{m 0}(t)$. In the discrete wavelet analysis of the signal $f(t) \in L^{2}$ we determine the inner products of the signal $f(t)$ and the sequence of functions $\psi_{m n}$. These inner products are known as wavelet coefficients. The discrete wavelet expansion of the signal $f$, which is the inverse discrete wavelet transform, can be expressed as

$$
f(t)=\sum_{m, n}\left(f, \psi_{m n}\right) \psi_{m n}=\sum_{m} \sum_{n} d_{m}[n] \psi_{m n},
$$

where the wavelet coefficients $d_{m}[n]=\left(f, \psi_{m n}\right)$ represent the common features of the signal $f$ and wavelet $\psi_{m n}$. The parameters $m$ and $n$ allow to access the particular signal features. The parameter $n$ is used to localize the requested time instant and the parameter $m$ allows to choose the scale level or frequency range, in which we wish to examine the signal frequency spectrum. Let us now concentrate on the interpretation of (10). For a fixed value of $m$, the right-hand side of this equation represents an orthogonal projection of $f$ onto a subspace $W_{m} \subset L^{2}(\mathbf{R})$. Denoting this projection by $P_{W_{m}} f$, we can represent (10) as

$$
f=\sum_{m=-\infty}^{m=J} P_{W_{m}} f+\sum_{m=J+1}^{\infty} P_{W_{m}} f .
$$

We can treat the second sum as an orthogonal projection $P_{V_{J}} f$ of $f$ onto certain subspace $V_{J} \subset L^{2}(\mathbf{R})$. We can rewrite (11) as

$$
f=\sum_{m=-\infty}^{m=J} P_{W_{m}} f+P_{V_{J}} f .
$$

This leads to the following relation:

$$
V_{j}=V_{j+1} \oplus W_{j+1} \quad, \quad j \in \mathbf{Z},
$$

which means that $V_{j+1}$ is the orthogonal complement of $W_{j+1}$ in $V_{j}$.

If the set $\{\varphi(t-n) ; n \in \mathbf{Z}\}$ is an orthonormal basis in $V_{0}$, then we call $\varphi$ the scaling function and we define an orthonormal dyadic base in $V_{j}$ as

$$
\varphi_{j n}(t)=2^{-j / 2} \varphi\left(2^{-j} t-n\right), n \in \mathbf{Z}
$$

then we can rewrite (12) as

$$
f(t)=\sum_{j=-\infty}^{J} \sum_{n \in \mathbf{Z}} d_{j}[n]+\sum_{n \in \mathbf{Z}} a_{J}[n] \varphi_{J n},
$$

where $a_{J}[n]=\left(f, \varphi_{J n}\right)$ and is known as the approximation of the signal $f$ at the level $J$. This is the celebrated multiresolution representation of the function $f$.

We can approximate the signal $f$ by its projection onto some subspace $V_{l}$ and then, we obtain

$$
f(t) \cong \sum_{j=l}^{J} \sum_{n \in \mathbf{Z}} d_{j}[n]+\sum_{n \in \mathbf{Z}} a_{J}[n] \varphi_{J n} .
$$

Equation (16) is an approximate multiresolution representation of the signal $f(t)$. To make this multiresolution representation complete, let us note that

$$
\begin{aligned}
L^{2}(\mathbf{R}) & =V_{-\infty} \supset \ldots \supset V_{l} \supset \ldots \supset V_{J} \supset \ldots \supset V_{\infty} \\
& =\{\varnothing\} .
\end{aligned}
$$

In each step of the process of the multiresolution analysis, we obtain the detail of a signal, which represents the projection of its previous approximation onto a subspace $W_{j}$ with the subscript increased by 1 and the new approximation, which represents the projection of the previous approximation onto the subspace $V_{j}$ with the subscript increased by one. Finally, when we stop the process, the signal representation consists of a sequence of details and the last approximation. In the next 
section, we only present a subset of the details. We chose the $8^{\text {th }}$-order Symmlet as the analyzing wavelet for the multiresolution analysis. High-order Symmlet wavelets achieve the closest approximation of exact symmetry and linear phase of the wavelet families that are useful with the discrete transform. We desired to minimize the phase distortion in order to maintain the temporal relationships between signals in the detail band as close as possible. The Fourier transform of the $8^{\text {th }}$-order Symmlet wavelet is plotted in Figure 6. It can be seen that the passbands are wider than the Morlet in Figure 4.

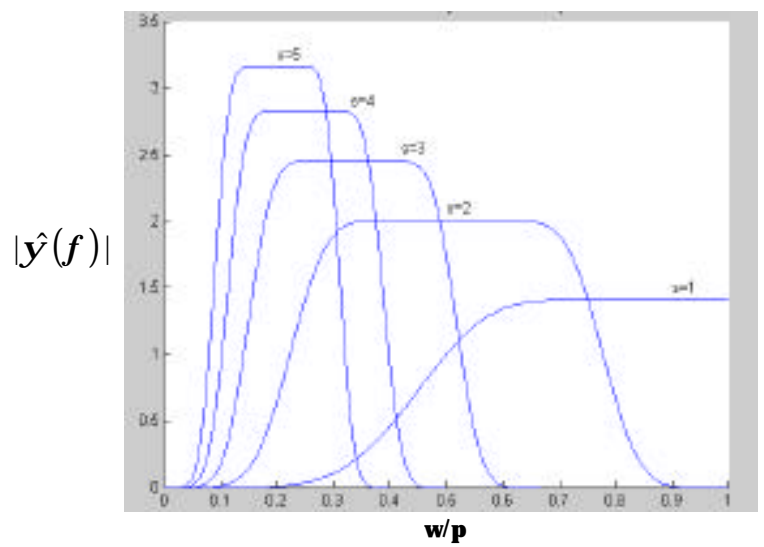

Figure. 6 Magnitude of the Fourier transform of the $8^{\text {th }}$-order Symmlet wavelet

\section{WAVELET ANALYSIS OF RIGID AND FLEXIBLE TURBINE DESIGNS}

We analyzed observed representative turbulence and flap load signals from both rigid and very flexible turbines using both the continuous and discrete wavelet transforms (for multiresolution analysis). The inflow measurements were limited to a single point at or near hub height upstream of the turbines. We used the Matlab Wavelet Toolbox as the primary analysis software for this research.

\section{Rigid Turbine}

We analyzed the turbulence excitation and rotor aerolelastic response of an upwind, three-bladed Micon 65/13 turbine located in San Gorgonio Pass of California. The instantaneous Reynolds or shearing stress components of the inflow were measured at about hub-height and 1.5-rotor diameters upstream. A multi-axis sonic anemometer with a measurement bandwidth of $5 \mathrm{~Hz}$ and a sampling rate of 16/s was used. The response variable is the root flap-bending load measured on one of the blades. The load signal was sampled at $32 / \mathrm{s}$ but a pre-sampling filter effectively limited the bandwidth to about $13 \mathrm{~Hz}$.
The blade was an NREL Thin Airfoil ${ }^{5}$ prototype consisting of S806A, S805A, and S807 airfoil shapes. The turbine rotor was $17 \mathrm{~m}$ in diameter, a hub height of $23 \mathrm{~m}$, and turned at $48 \mathrm{rpm}$. It was located at Row 37 within a 41-row wind farm.

An example of the analysis is presented in Figures 7, 8, and 9. We analyzed a record length of $60 \mathrm{~s}$ using both the continuous wavelet transform and multiresolution analysis (discrete transform) in order to more closely examine the loading transients and their excitation presented earlier in Figure 2. In order to achieve greater frequency resolution at the higher frequencies with the wavelet transforms, we oversampled the original signals to achieve a final sampling rate of $240 / \mathrm{s}$ by linear interpolation. The continuous transform, using the Morlet analyzing wavelet, was calculated for a range of scales in steps of 5 between 5 and 575 . Using the attributes of the Morlet wavelet, a scale value of 5 corresponds to a center frequency of 31.197 and bandwidth of 6.497 Hz. For a scale of 575, the corresponding frequencies were 0.332 and $0.056 \mathrm{~Hz}$, respectively.

The multiresolution analysis using the discrete wavelet transform was calculated using an $8^{\text {th }}$-order Symmlet analyzing wavelet to nine levels of detail. The first three detail bands (with frequency ranges of $60-120 \mathrm{~Hz}, 30-60 \mathrm{~Hz}$, and $15-30 \mathrm{~Hz}$ ) were ignored as their minimum frequency exceeded the effective 13$\mathrm{Hz}$ limitation of the original signals. The remaining six detail bands are referred to as B1 to B6. Table 1 summarizes the frequency ranges of each detail band and characteristic turbine modal responses that reside within each.

An analysis summary of the full 60-second record is presented in Figure 7. The time histories of the hub-height wind speed, Reynolds-stress components, and flap load signals are placed at the top. Immediately below the time histories is the continuous wavelet transform analysis of the flapwise signal and its corresponding multiresolution analysis below that.

The dark areas on the continuous transform display represent frequency bands containing high values of stress energy. The darker the band, the higher the dynamic stresses at the blade root. There is considerable low-frequency stress energy in the 0.33 - to $0.7 \mathrm{~Hz}$ frequency range $(0.4$ to $0.9 \mathrm{P}$, where $\mathrm{P}$ is the blade passage frequency of $0.8 \mathrm{~Hz}$ ) for the first $27 \mathrm{~s}$. A strong broadband response is associated with the load peak between 12 and 18 s; i.e., considerable stress energy extending up to10 $\mathrm{Hz}$ ( 13P). A similar, though not as intense, response is associated with the load peak between 30 and 32 s. The broad period of large flap amplitude activity 
Table 1. Multiresolution Analysis Detail Frequency Ranges for Micon 65 Turbine

\begin{tabular}{|c|c|l|}
\hline $\begin{array}{c}\text { Detail } \\
\text { Band }\end{array}$ & $\begin{array}{c}\text { Cyclic } \\
\text { Frequency } \\
\text { Range } \mathbf{( H z )}\end{array}$ & \multicolumn{1}{c|}{ Characteristic Modal Responses } \\
\hline B1 & $7.5-15.0$ & Rotor $2^{\text {nd }}$ flap bending; $2^{\text {nd }}$ asymmetric flap bending \\
\hline B2 & $3.75-7.5$ & Rotor $1^{\text {st }}$ lag bending; $2^{\text {nd }}$ asymmetric lag bending \\
\hline B3 & $1.875-3.75$ & $\begin{array}{l}\text { Rotor } 1^{\text {st }} \text { symmetric flap bending, } 1^{\text {st }} / 2^{\text {nd }} \text { asymmetric flap bending; tower fore/aft } \\
\text { and side/side asymmetric bending }\end{array}$ \\
\hline B4 & $0.938-1.875$ & Tower $1^{\text {st }}$ fore/aft and side/side bending \\
\hline B5 & $0.469-0.938$ & $1-\mathrm{P}$ \\
\hline B6 & $0.234-0.469$ & \\
\hline
\end{tabular}

from about 5 to $32 \mathrm{~s}$ is dominated by frequencies in the B4 and B5 detail bands (tower motions). These bands include the blade passage frequency (1-P) and the $1^{\text {st }}$-tower modes. A careful examination of the peak response between 12 and $18 \mathrm{~s}$ shows strong responses in detail bands $\mathrm{B} 2, \mathrm{~B} 3, \mathrm{~B} 4$, and $\mathrm{B} 5$ of the multiresolution analysis that correspond to the broadband response indicated by the continuous transform above. Thus during this load peak, the modal responses within the frequency range defined by the detail bands were simultaneously or coherently excited.

The first $20 \mathrm{~s}$ of the record is in Figure 8 using the same format as Figure 7. It provides a closer examination of the record. The analysis describes the evolution of the flap load signal leading up to the large excursions between 14 and about $18 \mathrm{~s}$. The character of the flap signal changes simultaneously with the peaks in the inflow Reynolds stresses at about $5 \mathrm{~s}$. During this period, there is significant response in the B4 and B5 detail bands ( 0.47 to 1.88 $\mathrm{Hz}$ or 0.6 to $2.3 \mathrm{P}$ ) with occasional bursts into the $\mathrm{B} 3$ band (2.3 to 4.7P). Many of the lower rotor modes are located in the B3 band (see Table 1). The significant broadband response occurring between 14 and $15 \mathrm{~s}$ appears to be associated with the increased levels of coherent turbulence activity as indicated by the Reynolds stress time histories.

The details of the inflow turbulence (Reynolds stress) and rotor flap response are plotted in Figure 9. Here, in addition to the time histories of the Reynolds stress components, the continuous wavelet transforms of each stress component and the flap signal are presented. The stress component diagrams indicate that there is considerable broadband energy associated with these bursts of coherent turbulence that are being ingested by the turbine rotor. It appears that the first burst near $5 \mathrm{~s}$ starts the rotor and tower oscillating at the various lower modal frequencies. The second burst, beginning about $12 \mathrm{~s}$ and lasting until $15 \mathrm{~s}$, is responsible for adding the additional energy to cause the broadband loading peak between 14 and $15 \mathrm{~s}$. The equivalent turbulent wavelengths for the Reynolds stresses are the order of 1 to 4 meters or $6 \%$ to $23 \%$ of the rotor diameter. Thus coherent turbulence structures whose space scales are less than a quarter of the rotor diameter can play an important role in peak load responses.

\section{Flexible Turbine}

We analyzed the turbulence excitation and rotor aeroelastic response of a flexible, two-bladed, downwind turbine. The turbine was a Carter/Cannon Wind Eagle CWE300 pre-prototype ${ }^{5,6}$ installed at the National Wind Technology Center (NWTC). The instantaneous Reynolds stresses of the inflow are measured two rotor diameters upstream using a multi-axis sonic anemometer with a measurement bandwidth of $10 \mathrm{~Hz}$, a $12.5-\mathrm{Hz}$ pre-sampling filter, and a sampling rate of $200 / \mathrm{s}$. The response variable is the flapwise bending measured near the hub on the flexible inner spar (flexbeam) of the turbine rotor. This signal was passed through a $40-\mathrm{Hz}$ pre-sampling filter and sampled at 200/s. The turbine rotor was $29.3 \mathrm{~m}$ in diameter, a $48.8 \mathrm{~m}$ hub height, and turned at $57 \mathrm{rpm}$. The turbine was operated with no others upstream. The segment analyzed came from a longer 10-minute record in which the hub-height average wind speed was $18.33 \mathrm{~m} / \mathrm{s}$ and the flow was slightly stable with a turbine layer Richardson number value of +0.031 . To better compare with the numerical simulation of this record, the bandwidth of the turbine signals prior to analysis was low-pass limited to $30 \mathrm{~Hz}$.

Again, a 60-s record was analyzed and the results are presented in Figure 10 in the same format as Figures 8 and 9. As previously, the sampling rate was increased to $240 / \mathrm{s}$ by linear interpolation to produce an identical scale range for the continuous transform using the Morlet analyzing wavelet. 


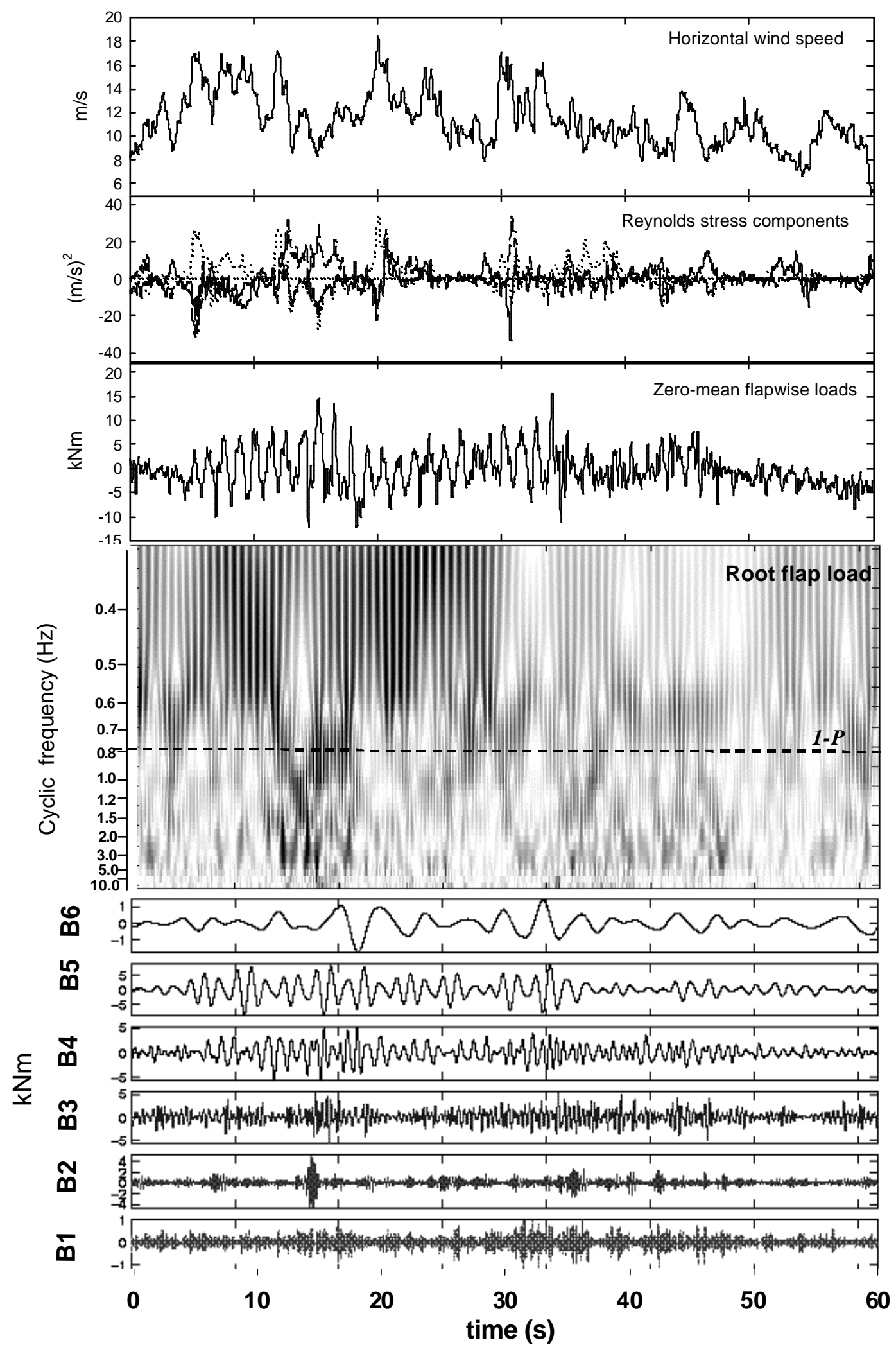

Figure 7. Time and wavelet analysis of rigid turbine turbulence response 


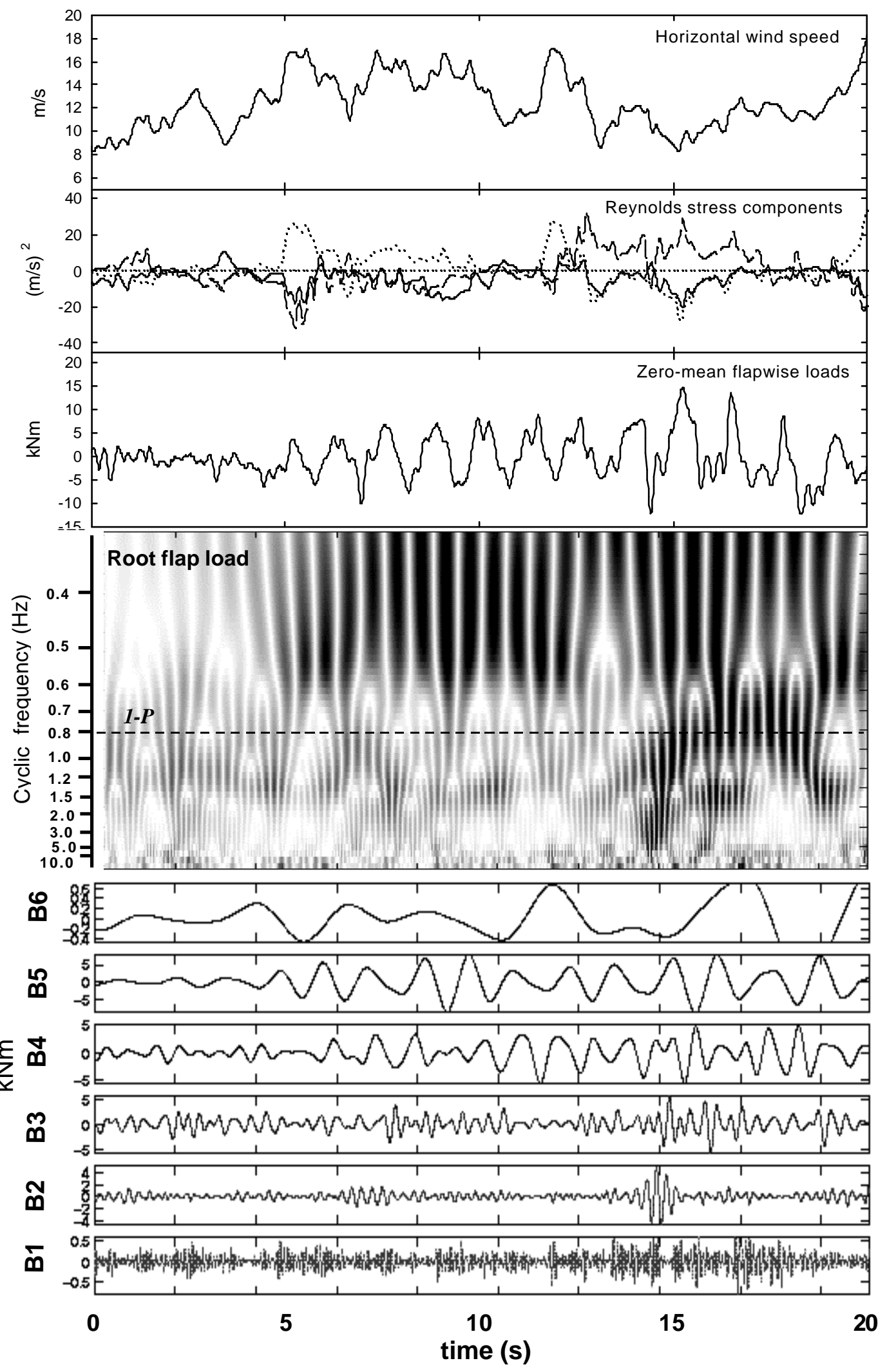

Figure 8. Time and wavelet analysis of detail of rigid turbine response 


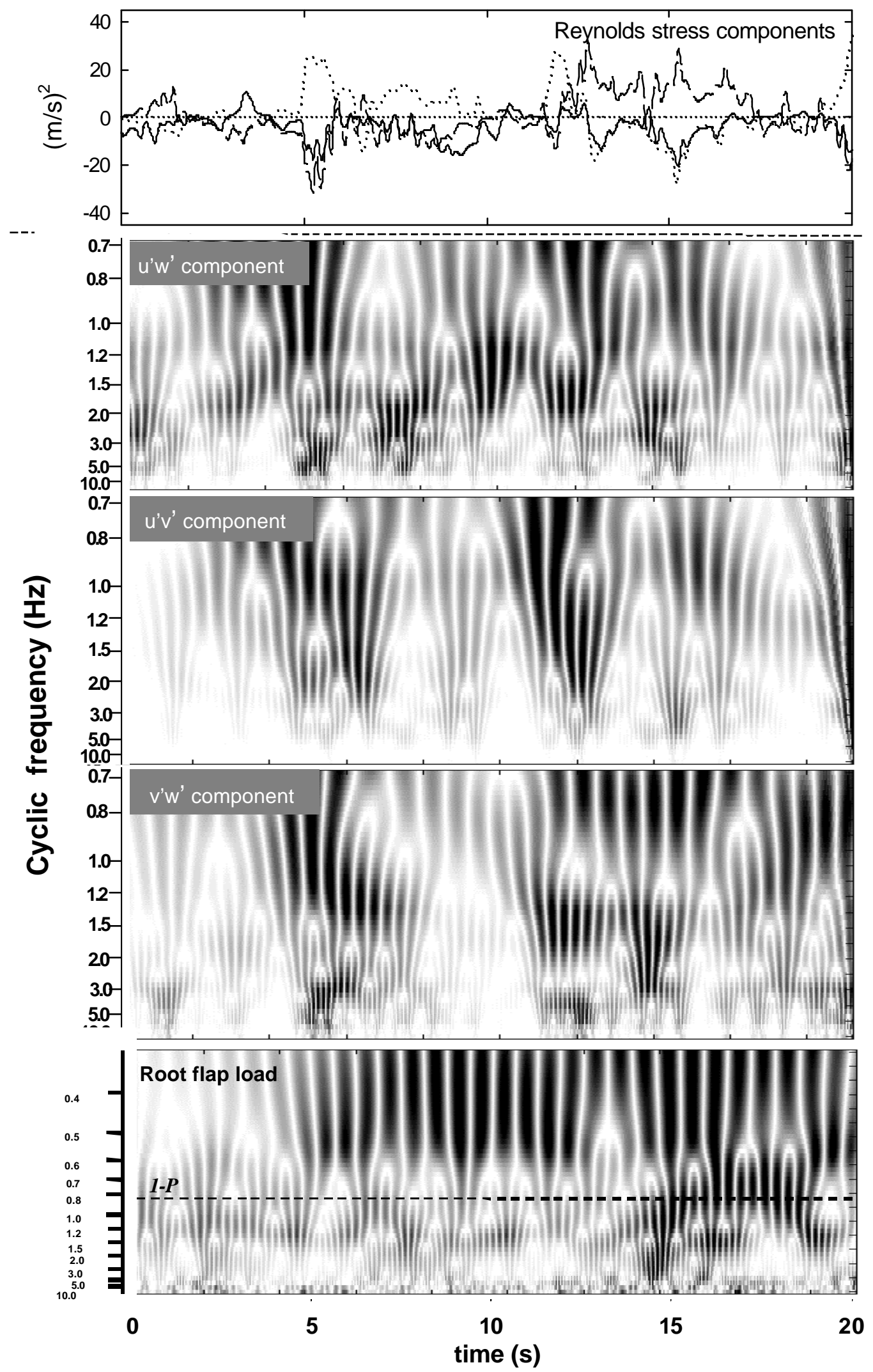

Figure 9. Continuous wavelet analysis of inflow and flap response for rigid turbine detail 
Table 2. Multiresolution Analysis Detail Frequency Ranges for CWE300 Turbine

\begin{tabular}{|c|c|c|}
\hline $\begin{array}{l}\text { Detail } \\
\text { Band }\end{array}$ & $\begin{array}{c}\text { Cyclic } \\
\text { Frequency } \\
\text { Range (Hz) }\end{array}$ & Characteristic Modal Responses \\
\hline B1 & $15.0-30.0$ & Rotor $1^{\text {st }} / 2^{\text {nd }}$ torsion bending; $3^{\text {rd }}$ symmetric lag bending \\
\hline B2 & $7.5-15.0$ & Flexbeam $2^{\text {nd }}$ flap bending; blade shell $4^{\text {th }}$ flap bending \\
\hline B3 & $3.75-7.5$ & $\begin{array}{l}\text { Rotor } 3^{\text {rd }} \text { symmetric and asymmetric bending; } 2^{\text {nd }} \text { asymmetric lag bending; blade } \\
\text { shell } 2^{\text {nd }} \text { flap bending }\end{array}$ \\
\hline B4 & $1.875-3.75$ & Rotor $2^{\text {nd }}$ asymmetric flap bending; blade shell $1^{\text {st }}$ flap bending \\
\hline B5 & $0.938-1.875$ & $\begin{array}{l}\text { Rotor } 1^{\text {st }} \text { asymmetric flap bending; rotor } 2^{\text {nd }} \text { symmetric flap bending; tower } 1^{\text {st }} / 2^{\text {nd }} \\
\text { fore/aft and side/side bending; drive train } 1^{\text {st }} \text { bending; blade shell } 1^{\text {st }} \text { flap bending }\end{array}$ \\
\hline B6 & $0.469-0.938$ & Rotor $1^{\text {st }}$ asymmetric lag bending; $1-\mathrm{P}$ \\
\hline B7 & $0.234-0.469$ & Rotor $1^{\text {st }}$ symmetric flap bending \\
\hline
\end{tabular}

As previously, the sampling rate was increased to $240 / \mathrm{s}$ by linear interpolation to produce an identical scale range for the continuous transform using the Morlet analyzing wavelet. As before, an $\delta^{\text {th }}$-order Symmlet wavelet was applied to compute the multiresolution analysis with the discrete transform of the signals. An additional detail band was included $(15-30 \mathrm{~Hz})$ because of the wider signal bandwidth associated with this turbine. The frequency ranges for each detail band and the characteristic modal responses are listed in Table 2. A comparison of the contents of Tables 1 and 2 will reveal the much lower frequencies associated with many of the flexible-turbine mode shapes relative to those seen in the much more rigid design.

The record from the flexible turbine has two periods of oscillating loads. The oscillation in the first $12 \mathrm{~s}$ appears to be associated with a broad peak in the wind speed that contains a very complex turbulent structure. The second oscillation envelope appears to be in response to the turbulent structure seen at about $30 \mathrm{~s}$ into the record. As previously, the first 20 seconds is detailed in Figure 11. Here it is clear that the large oscillation is related to the turbulent structure between 2 and $11 \mathrm{~s}$. This is made even more obvious by the continuous transforms of the individual shear stress components and their relationship to the flapwise load response presented in Figure 12. From these graphs and those from the Micon 65, one of the major consequences of the rotor encountering these organized turbulent regions is that the higher-order mode shapes are energized in a phase coherent manner. The organized inflow excitation results in large load excursions when the peaks in the constituent modal responses come into phase alignment. This can be seen by examining the signals in detail bands B2 through B5 in the multiresolution graphs at the bottom of Figures 8 and 11.

\section{WAVELET ANALYSIS OF A SIMULATED FLEXIBLE TURBINE RESPONSE}

One of the major obstacles in interpreting the role of coherent turbulence regions and their impact on a turbine rotor when using normally available observed data is that the excitation is usually only measured at fixed locations in space. The rotor, however, is continually passing through a much larger area and rotationally sampling the turbulent field within that area. To obtain at least an estimate of what a rotating blade may encounter as it passes through a region of coherent turbulence, we used a numerical simulation of the CWE300 turbine developed by Wright. $^{6}$ The inflow boundary conditions for the simulation were chosen to be as close as possible to those associated with the collected data presented in the previous section. A special model calculation was made in which time histories of a range of aerodynamic parameters (angle-of-attack, normal and tangential forces, and lift and drag coefficients) for each of the outer seven blade sections was made available in rotational space. In addition to the aerodynamic parameters, the rotationally sampled, three wind components present at each blade section were also output. The turbulent inflow to the model was generated by the SNLWIND-3D code. ${ }^{7}$ This code has the ability to produce complex, turbulent structures similar to those seen in the observed data discussed previously.

The loads on the turbine during the actual observations were often quite high due to the strong and very turbulent winds in which the turbine was operating. Gusts exceeding $27 \mathrm{~m} / \mathrm{s}$ were seen during the 10 minutes of actual data collection. We examined the simulated record for an example of a large flap load excursion in order to study the characteristics of the inflow in both fixed and rotationally sampled space. Figure 13 displays the time and wavelet analysis of a 20 -second record in 


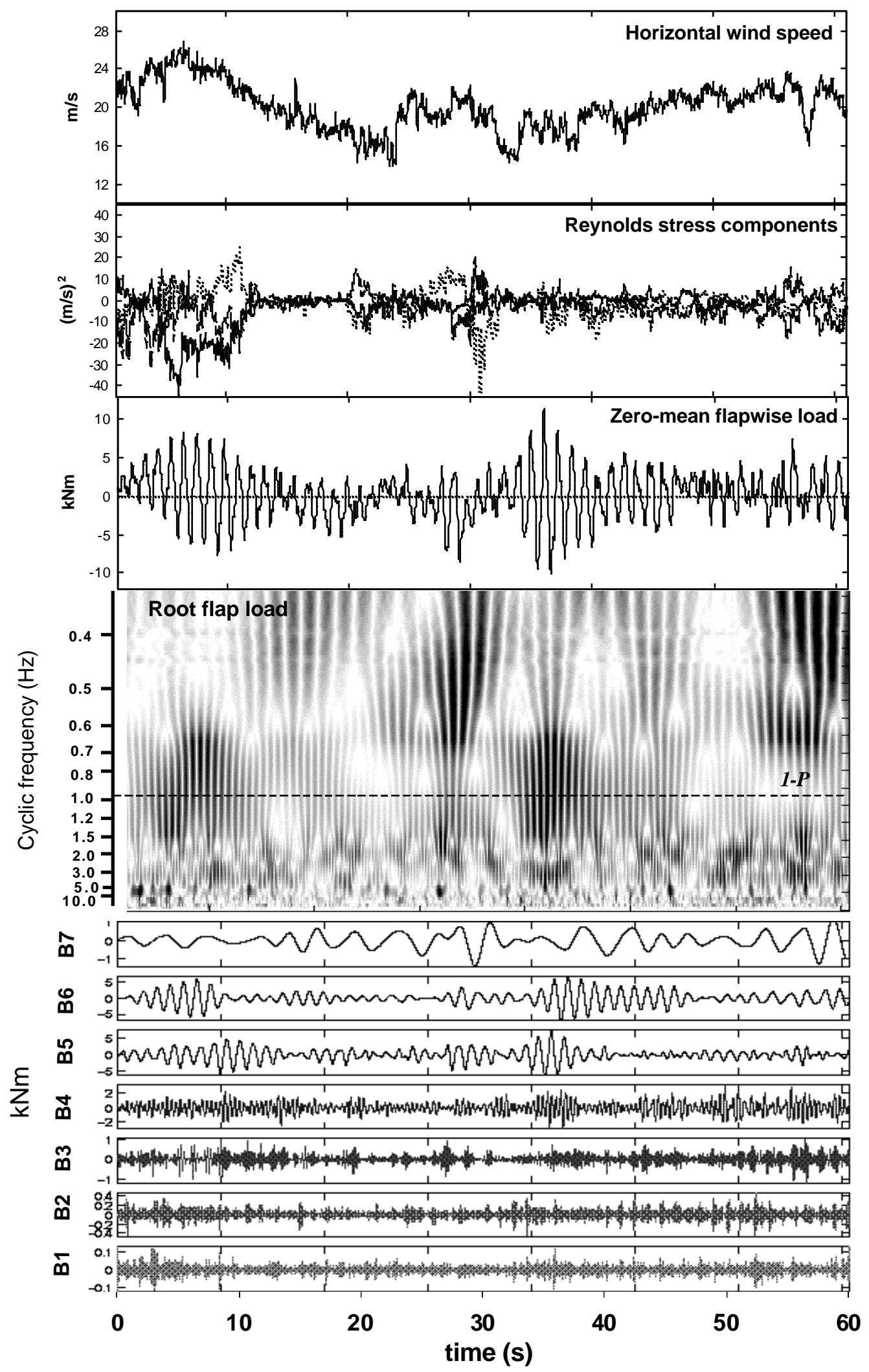

Figure 10. Time and wavelet analysis of detail of flexible turbine turbulence response 


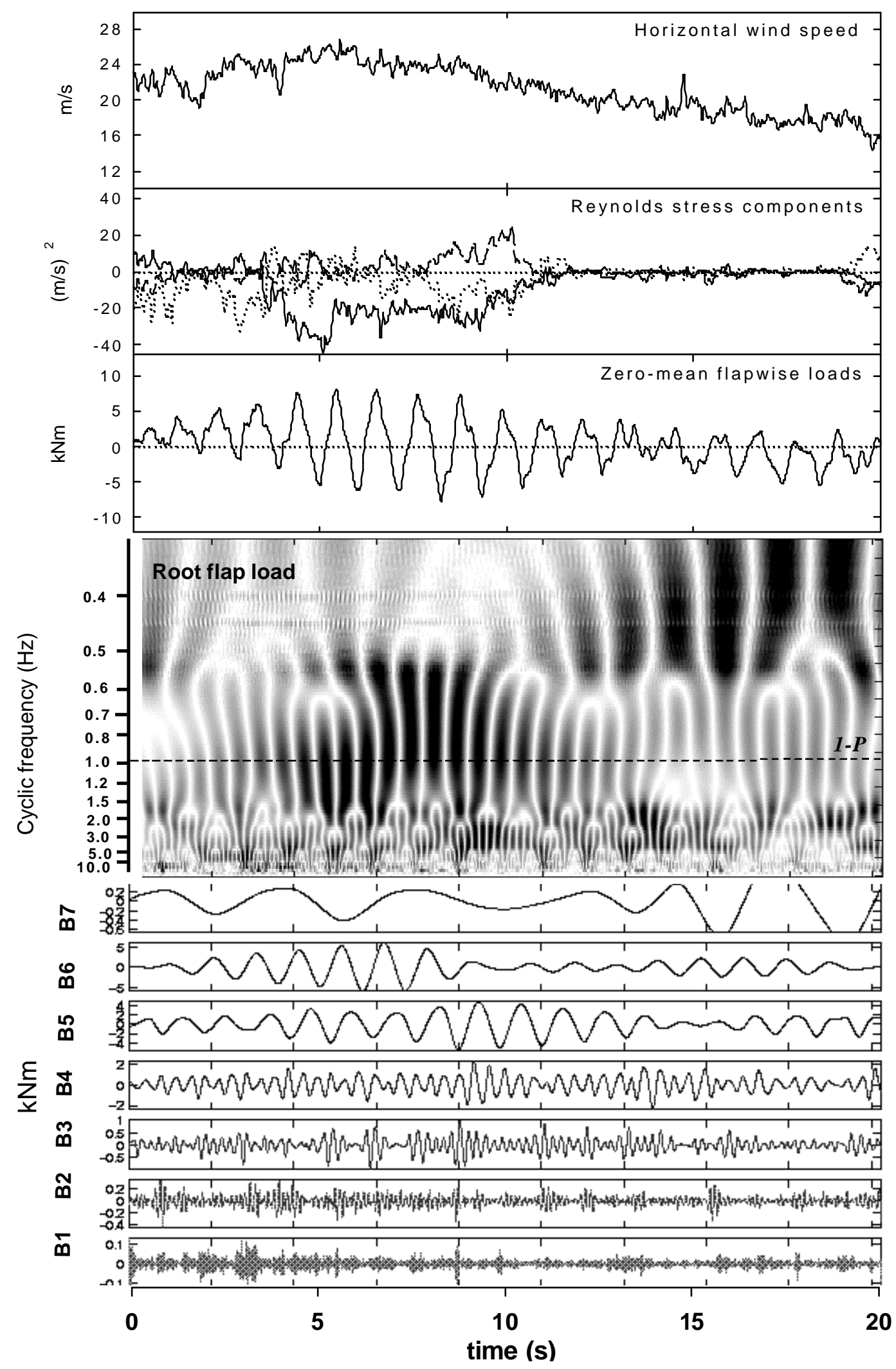

Figure 11. Time and wavelet analysis of detail of flexible turbine response 


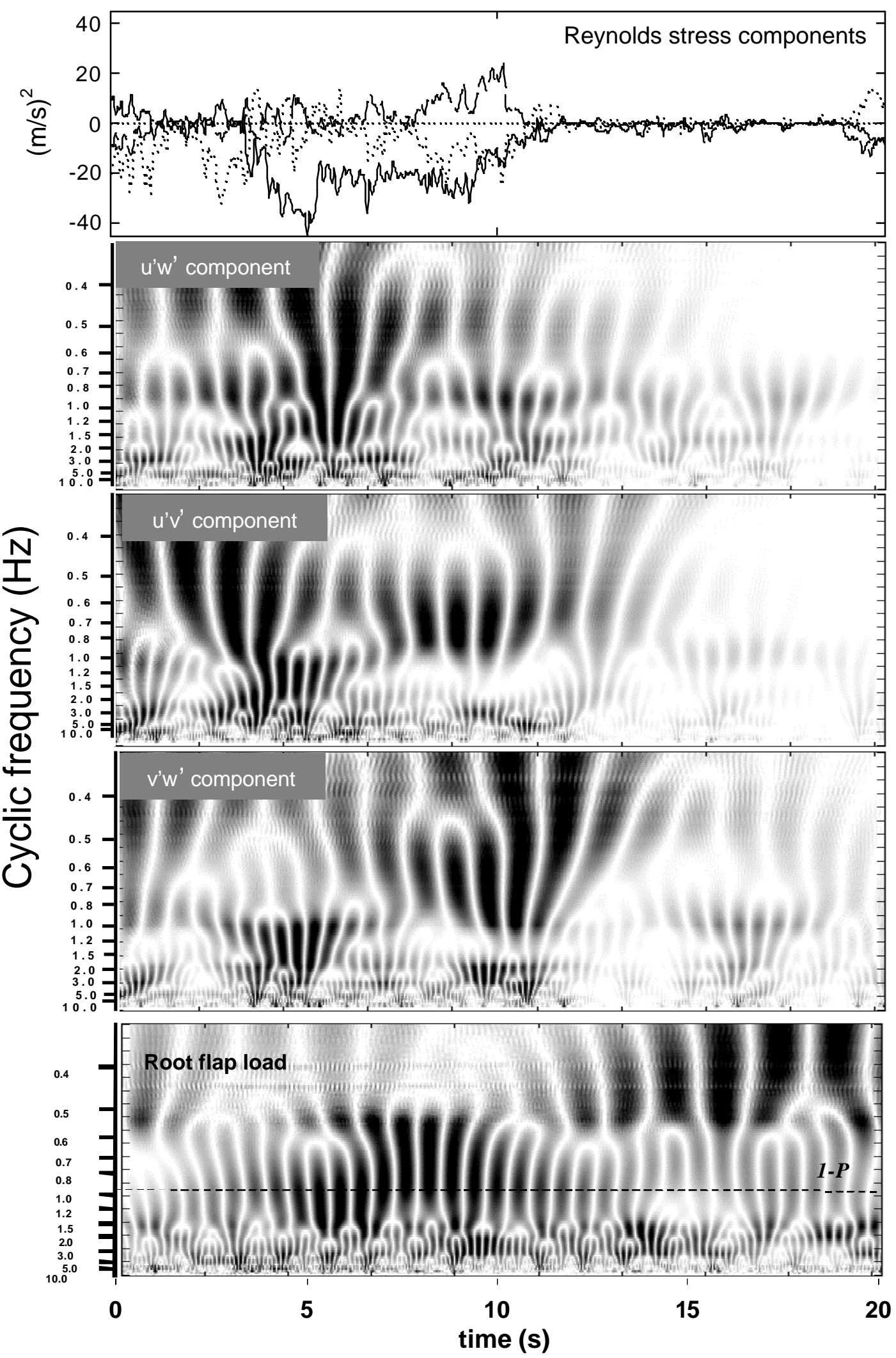

Figure 12. Continuous wavelet transform analysis of turbulence excitation for flexible turbine 
which large flap excursions were predicted. As in the observed data, a broad period of high winds contains a very complex turbulent structure. The high loads are confined to four blade passages through the complex turbulence region between 7 and $12 \mathrm{~s}$. Again, there is a broadband response to this turbulent region as is seen in both the continuous and multiresolution wavelet analyses in the lower portion of Figure 13.

In Figure 14, we compare the turbulence excitation and response in both fixed and rotational space. In the two upper panels, we compare the instantaneous Reynolds stress components as seen in fixed space at the rotor hub with those seen by the $78 \%$-span blade station as it rotates through the turbine inflow area. The rotational picture is quite different from that in fixed space though the presence of complex turbulence structures can be identified. The continuous wavelet transform analysis of the normal force predicted for the $97 \%$-span station is presented in the third panel. The analysis shows that there is substantial energy concentrated in the 0.9 to 7 $\mathrm{Hz}(0.95$ to $7 \mathrm{P})$ range and possibly above during the periods of maximum excitation. This is the frequency range in which the first and second symmetric and asymmetric rotor mode shapes reside. These results suggest that one of the consequences of a blade passing through a coherent, turbulent field will be the excitation of the first and higher order symmetric and asymmetric rotor modes. This result is consistent with what Tangler et al. ${ }^{8}$ found in analyzing the Micon 65 data. It was noted that coherent turbulence excited the first asymmetric mode of the blade that contributed to large flapwise responses

\section{CONCLUSIONS}

We applied both the Windowed Fourier and wavelet transforms to both inflow turbulence (Reynolds stresses) and a turbine key rotor response parameter (root flap loads). We found, while each approach has its advantages and disadvantages, the Windowed Fourier or Short-Time Fourier Transform did not offer us any additional information over what was available from the continuous and discrete wavelet transforms. Since the turbines we analyzed were both of constant-speed design, this conclusion may not extend to machines operating in a variable speed mode. As expected, with proper signal preparation, i.e., over-sampling, both the continuous and discrete wavelet transforms provided insights into the turbulence/rotor interaction that could not be achieved from conventional spectral analysis.
Further, our initial application of the wavelet analysis techniques for interpreting the turbulence/rotor interaction in the rotating frame derived from numerical simulations appears quite promising.

Our analysis of the both the rigid and flexible turbines has shown that a coherent or broadband structural response occurs in a rotor ingesting a coherent patch of turbulence. The analysis of the inflow revealed that such patches contain a broad range of frequencies (turbulent eddy wavelengths) that contribute to the excitation of a wide range of modal responses in the turbine rotor and supporting structure. The multiresolution analyses of the rotor flapwise responses revealed that the load peaks occur when the various modal frequencies also reach peak values in phase or unison. The first and second symmetric and asymmetric rotor modes appeared to be most susceptible to such excitation. It was found that the constituent turbulent eddies of coherent structures, whose equivalent space scales are less than a quarter of the rotor diameter, play a major role in developing peak load responses.

Our results indicate that the presence of coherent turbulent structures, as revealed by the inflow Reynolds stress field, is a major contributor to large load excursions and the accompanying fatigue damage. We have demonstrated that wind gusts can contain a very complex turbulence structure that in turn can provide broadband excitation to a turbine rotor passing through it. Thus when assessing a potential wind energy site or simulating turbulent inflows for load assessments on new turbine designs, the frequency and intensity of such flow structures needs to be evaluated in order to assess potential fatigue damage accumulation.

\section{FUTURE WORK}

We plan to continue the analysis of the turbulence/rotor interaction using numerical simulations and, if available, observed data derived from the Unsteady Aerodynamics Experiment being conducted by the National Wind Technology Center. We also wish to apply these techniques to evaluating the load response characteristics from variable speed rotors.

\section{ACKNOWLEDGEMENTS}

The authors wish to acknowledge the contributions of Alan Wright and Kirk Pierce of NREL to this project. 


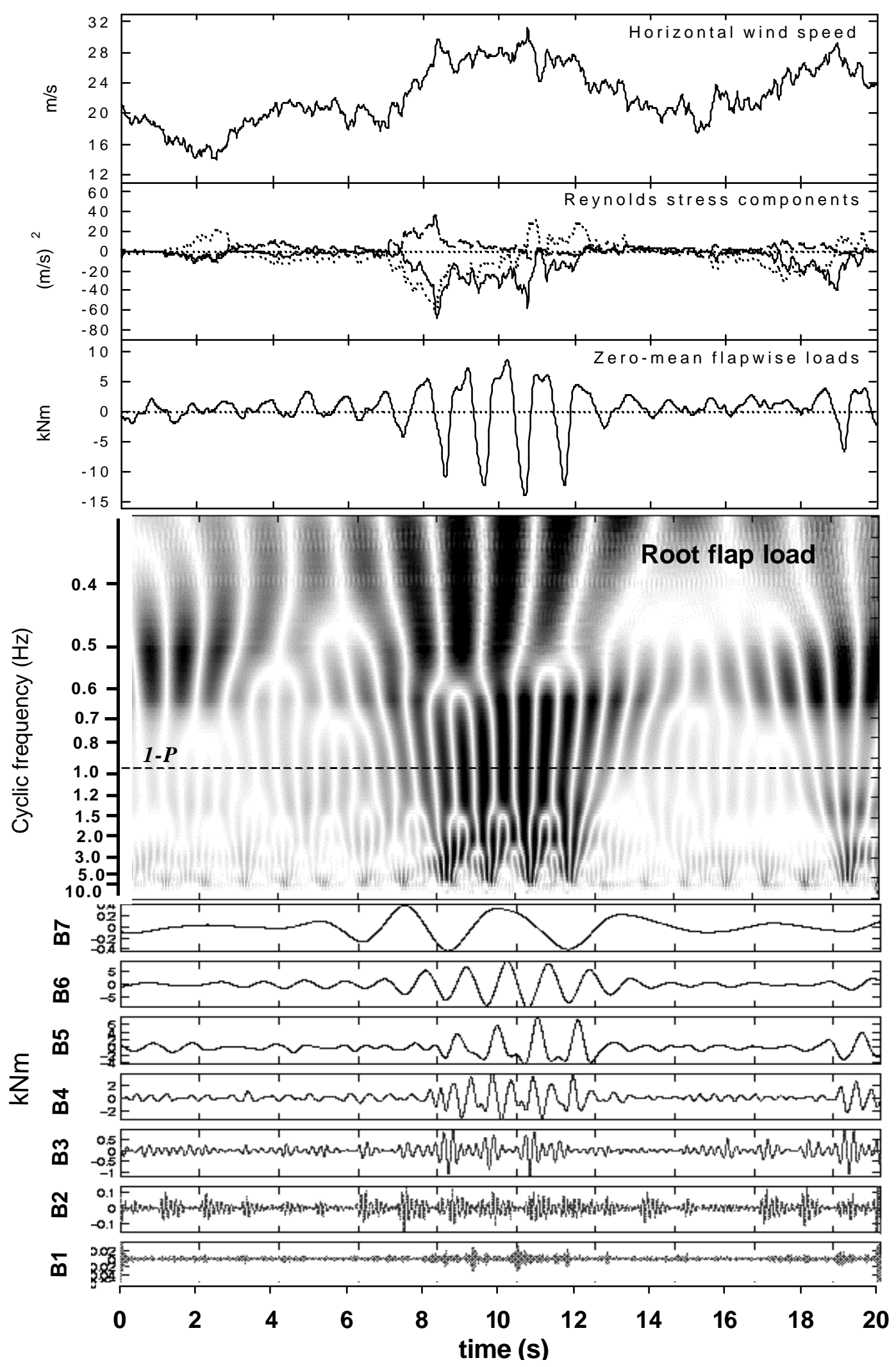

Figure 13. Time and wavelet analysis of simulated turbulence/rotor interaction 


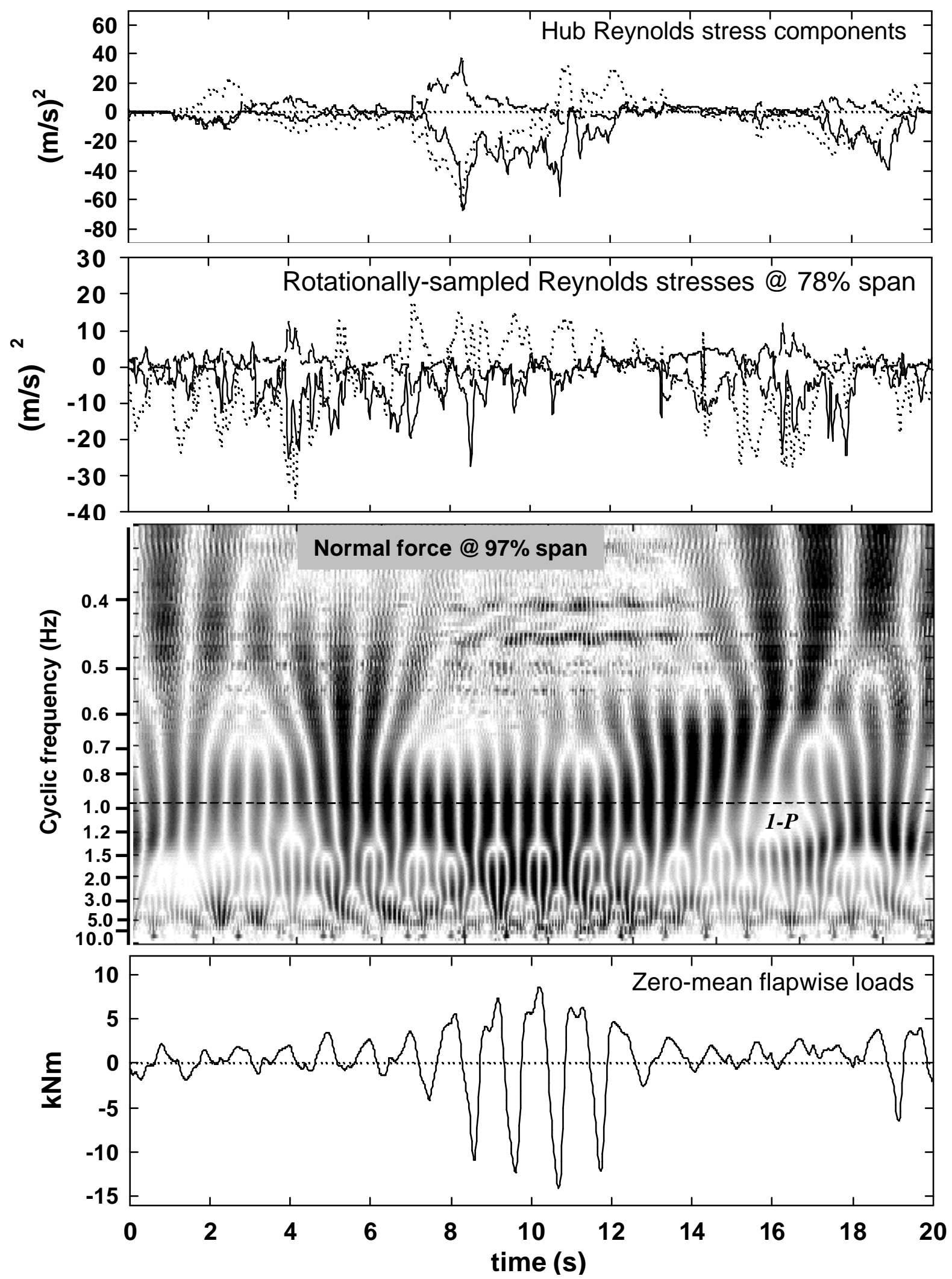

Figure 14. Time and continuous wavelet analyses of fixed and rotating excitation and response 


\section{REFERENCES}

1. Kelley, N.D. "The Identification of Inflow Fluid Dynamics Parameters That Can Be Used to Scale Fatigue Loading Spectra of Wind Turbine Spectral Components," NREL/TP-442-6008, Golden, CO: National Renewable Energy Laboratory, 1993.

2. Kelley, N.D. "A Case for Including Atmospheric Thermodynamic Variables in Wind Turbine Loading Parameters Identification," NREL/CP-500-26829, Golden, CO: National Renewable Energy Laboratory, 1999.

3. Mallat, S. A Wavelet Tour of Signal Processing, Academic Press, San Diego, CA, 1998.

4. Tangler, J., Smith, B., Jager, D., McKenna, E. and Allread, J. "Atmospheric Performance Testing of the Special Purpose Thin Airfoil Family: Preliminary Results," Proc. WindPower '89, NREL-/TP-2573628, Golden, CO: National Renewable Energy Laboratory, 1989.

5. Kelley, N. D., Wright, A. D., and Osgood, R. M."A Progress Report on the Characterization and Modeling of a Very Flexible Turbine Design," $18^{\text {th }}$ ASME/AIAA Wind Energy Symposium, NREL/CP500-25513, Golden, CO: National Renewable Energy Laboratory, October 1998.

6. Wright, A. D. and Kelley, N. D. "Validation of a Model for a Two-Bladed Flexible Wind Turbine System," Proc. $3^{\text {rd }}$ ASME/JSME Joint Fluids Engineering Conference, San Francisco, CA, July 1823, 1999.

7. Kelley, N. D. "Full Vector (3-D) Inflow Simulation in Natural and Wind Farm Environments Using an Expanded Version of the SNLWIND (Veers) Turbulence Code," NREL/TP-442-5225, Golden, CO: National Renewable Energy Laboratory, 1993.

8. Tangler, J., Smith, B., Kelley, N., and Jager, D. "Measured and Predicted Rotor Performance for the SERI Advanced Wind Turbine Blades," Proc. WindPower '91, NREL/TP-253-4673, Golden, CO: National Renewable Energy Laboratory, 1990. 